\title{
New Directions in Thoracoscopy: Is the Future Fluorescent?
}

\author{
N.A. Maskell \\ North Bristol Lung Centre, Southmead Hospital, Bristol, UK
}

The origins of thoracoscopy date back 100 years, when Jacobaeus used a modified cystoscope to examine the thoracic cavity of patients with tuberculous pleurisy [1]. This early pioneer initiated the therapeutic application of thoracoscopy for lysis of pleural adhesions. The next major advance occurred in the 1950s when physicians started to perform lung biopsies for interstitial lung disease [2]. Then in 1963 Roche et al. [3] published the first report of the use of talc poudrage in pleurodesis of malignant pleural effusions. Today, thoracoscopy is routinely used in the diagnosis of malignant pleural disease, and talc poudrage remains the most efficacious pleurodesis agent [4]. Over the past decade, we have also seen the development of the semiflexible thoracoscope [5] and narrow band imaging [6] and the emergence of autofluorescence thoracoscopy [7].

In this issue of Respiration, Vandermeulen et al. [8] take another step forward. They describe a novel technique in which thoracoscopy is performed in an animal model after inhalation of nebulised sodium fluorescein. The pleural and lung surfaces were then inspected by white light thoracoscopy and fluorescein-enhanced autofluorescence thoracoscopy (FEAT), and regions of interest were examined histologically. They found that fluorescein accumulates in the subpleural space of better ventilated lung areas.

\section{KARGER}

Fax +4161306 1234 E-Mail karger@karger.ch www.karger.com
(C) 2010 S. Karger AG, Basel 0025-7931/10/0803-0188\$26.00/0

Accessible online at: www.karger.com/res
Administration of sodium fluorescein by aerosol caused a progressive increase in fluorescence intensity within the thoracic cavity. The authors found that fluorescein diffused widely into the visceral pleura, but concentrations were different within separate lung regions. They postulate that negative FEAT areas are likely to be due to regions of decreased ventilation due to atelectasis.

The major weakness of the study is the degree of chronic lung inflammation that tends to occur in healthy pigs. The use of another animal model may prove informative. Although the exact application of this method requires further study, FEAT may become an exciting tool in the study of the pathophysiology of primary spontaneous pneumothorax (see Vandermeulen et al. [8], this issue, fig. 5, p. 233).

Although autofluorescence thoracoscopy is still largely a research tool, this type of study is pivotal if we are to achieve in the next century what was achieved by our predecessors over the past 100 years. In the future, thoracoscopy is likely to become more than just an instrument for confirming pleural malignancy. However, this aspiration will only be achieved if we nurture lateral thinking and continue to encourage experimentation. 


\section{References}

1 Moisiuc FV, Colt HG: Thoracoscopy: origins revisited. Respiration 2007;74:344-355.

2 Brandt HJ, Loddenkemper R, Mai J: Atlas of Diagnostic Thoracoscopy. New York, Thieme, 1985.

3 Roche G, Delanoe Y, Moayer N: Talcage de la plevre sous pleuroscopie. J Fr Med Chir Thorac 1963;21:177-195.

4 Hooper C, Lee YCG, Maskell NA: British Thoracic Society Pleural disease guidelines. The investigation of an undiagnosed unilateral pleural effusion - 2010 update. Thorax, in press.
Ernst A, Hersh CP, Herth F: A novel instrument for the evaluation of the pleural space: an experience in 34 patients. Chest 2002;122: 1530-1534.

6 Schönfeld N, Schwarz C, Kollmeier J, Blum T, Bauer TT, Ott S: Narrow band imaging (NBI) during medical thoracoscopy: first impressions. J Occup Med Toxicol 2009;26: 24.
7 Belák J, Kudlác M, Cavarga I, Janík M, Sauka C: Autofluorescence videothoracoscopy our initial experience (in Slovak). Rozhl Chir 2007;86:558-561.

8 Vandermeulen L, Makris D, Mordon S, Goossens A, Marquette C-H, Haentjens P, Noppen $\mathrm{M}$ : Thoracoscopic findings and pharmacokinetics of inhaled fluroescein in a pig model. Respiration 2010;80:228-235. 